OPEN ACCESS

UNIVERSITY OF THE

WEST of SCOTLAND

UWS Academic Portal

\title{
An evolving gang model in contemporary Scotland
}

McLean, Robert

Published in:

Deviant Behavior

DOI:

10.1080/01639625.2016.1272969

Published: 01/01/2018

Document Version

Peer reviewed version

Link to publication on the UWS Academic Portal

Citation for published version (APA):

McLean, R. (2018). An evolving gang model in contemporary Scotland. Deviant Behavior, 39(3), 309-321.

https://doi.org/10.1080/01639625.2016.1272969

\section{General rights}

Copyright and moral rights for the publications made accessible in the UWS Academic Portal are retained by the authors and/or other copyright owners and it is a condition of accessing publications that users recognise and abide by the legal requirements associated with these rights.

Take down policy

If you believe that this document breaches copyright please contact pure@uws.ac.uk providing details, and we will remove access to the work immediately and investigate your claim. 
"This is an Accepted Manuscript of an article published by Taylor \& Francis Group in Deviant Behavior on 25/01/2017, available online: http://

www.tandfonline.com/10.1080/01639625.2016.1272969." 


\title{
An Evolving Gang Model in Contemporary Scotland
}

Robert McLean, Interdisciplinary Research Unit on Crime, Policing and Social Justice, School of Education, University West of Scotland, Ayr campus, KA8 0SX, UK.

Telephone:01292886000; Email: robert.mclean@uws.ac.uk

Keywords: Drug Dealing, Gangs, Organised Crime, Scotland, Territoriality

\begin{abstract}
Young street gangs (YSGs) in Scotland are considered recreational youth outfits bound up in issues of territoriality and protest masculinities. While YSGs occasionally engage in territorial violence they are nonetheless viewed as distinct entities from organised crime (OC). However, following qualitative interviews $(n=35)$ with offenders involved in $\mathrm{OC}$, namely illegal drug supply, the author concludes otherwise and presents evidence which suggests YSGs retain evolving capabilities. The author presents an evolving gang model in which the key sequential stages are outlined as recreational, criminal, and syndicate and argues that, aided by globalisation, gang organisation has become a means for gang business.
\end{abstract}

\section{Introduction}

\section{Revisiting The British Gangs}


Within the academic literature British gangs have traditionally been considered distinct from those found in North American. Rather than being presented as organised, structured, and involved in crime-for-profit activities British scholars instead emphasizes their own unique sub-cultures (Campbell and Muncer 1989; Downes 1966). Yet over the past decades or so, there has been a growth in fearful perceptions that US style gangs are extrapolating onto UK soil and proliferating across the country (Hallsworth and Brotherton 2011). This gang discourse has been brought about by complex processes apropos to cultural, economic and political globalisation (Pitts, 2008). Likewise, much of this gang revisiting has been enshrined in a gang talking discourse, primarily driven by the political establishment, mass media, and law enforcement as opposed to criminologists and sociologists (Hallsworth and Young 2008). This discourse is perhaps best epitomised by the response of the UK government to the 2011 summer riots, following which the Prime Minister, David Cameron, declared war against Britain's growing gang culture. This was promptly followed by the HM Government (2011) report 'Ending Gang and Youth Violence', which portrayed the urban gang as organised, inherently criminal, and corrosive to wider youth culture. Gang members were predominantly presented as young ethnic males from poor households adhering to countercultural values. In addition, cultural heritage was quickly affiliated with the corruption of indigenous white suburbia (Hallsworth and Brotherton 2011). The response of the British State has been to draw upon the US zero tolerance approach in order to curb gang activity. Needless to say this punitive approach sought to supress the gang as opposed to addressing those social and economic conditions which it may emanate from, if at all.

However, British academics have approached the gang revisiting with a considerably greater degree of caution than their political counterparts. The academic community has essentially dichotomized over the debate (Densley 2012): while some believe that UK gangs are increasingly adopting and replicating US gang models (Bennet and Holloway 2004; 
Bullock and Tilley 2003; Densley 2012; Harding 2014; Pitts 2012), others are more sceptical. This does not mean they necessarily outright deny the existence of such groupings but rather believe them to be very much the exception instead of the rule (Aldridge et al. 2008; Hallsworth 2014; Hallsworth and Young 2008). Regardless, while the gang revisiting has been gathering momentum in an Anglo-Welsh context, where academics seek to establish whether or not gangs really are organising as a means for gang business, this has not been the case in Scotland. Rather in Scotland, the outcome of the debate has already been largely decided by a number of complex reasons which have resulted in the predetermined belief that urban street gangs are distinct from organised crime (OC). A combination of factors captured within assumed gang history has led to the overly fixative gaze being placed upon young urban street gangs situated within the recreational stage of development. The author coins these urban street gangs under the umbrella terms Young Street Gangs (YSG) in order to summarize their description.

Much, if not all, contemporary gang research in Scotland is focused upon such recreational groupings. While this research is vital for understanding many aspects of youth delinquency in context, such as territorial violence, knife crime, and protest masculinities, this fixation has nonetheless proved detrimental to the identification of potential gang evolution. Scottish gang literature has essentially failed to identify potential gang evolution away from the recreational and towards the criminal. This article aims to bring the Scottish gang revisiting back into focus by moving beyond the recreational gang and outlining gang organisation as a means to gang business. In order to do so the article will first review contemporary Scottish gang literature to outline the foundations from which those processes incorporated into assumed gang history can be highlighted and discussed. The article will then outline the methodology used in the research, before presenting research findings in the form of two key themes titled gang organisation and gang business. These themes emerged from the 
research data following thematic analysis of data. These sections will outline the way in which gangs organise in response to natural maturity, external threats, and social pressures, and also how gangs conduct business primarily in the form of drug dealing proper. A discussion will then ensue in which the author will summarise findings and present an evolving gang model to account for Scotland's contemporary gang.

\section{An Academic Revisiting of Scotland's Gang}

While the UK Government acknowledges that residential areas found to be high in street gang activity are typically likewise found to be high in OC activity, in Scotland no such link is recognised, nor have attempts have been made to establish such correlations (National Crime Agency [NCA] 2013). This is particularly surprising given that Scotland's largest city, Glasgow, has more gangs than London, and also retains 70\% of OC within Scotland, $65 \%$ of which is directly related to drug dealing (Scottish Government 2015; Violence Reduction Unit [VRU] 2011). Instead YSGs and those individuals involved in OC remain distinct and independently unrelated entities. The VRU, 2011, report 'Glasgow's community initiative to reduce violence" argues that YSGs are "distinct from organised crime" (VRU 2011;7). In Scotland, groups or individuals involved in such behaviour are rendered to the sphere of OC. This is exemplified by Police Scotland's serious and organised crime criteria which states organised crime to "a) involve more than one person, b) is organised, meaning that it involves control, planning and use of specialist resources, c) causes, or has the potential to cause, significant harm, and d) involves benefit to the individuals concerned, particularly financial gain" (Scottish Government 2015:6). Criminal activity carried out in the group and seeking financial gain is deemed to be a Serious Organised Crime Group (SOCG). Ultimately, despite retaining many SOCG characteristics and often comprising of individuals which Farrington et al. (2009) would term persistent offenders - that is life long career criminals whom offend from a young age - 
the YSG is not recognised as having the capacity to become involved in, or evolve towards, such behaviour. Nor is there any correlation thought to exist between YSG members and those involved in OC. This view remains even though gang members across the board have generally been found to commit disproportionate levels of crime (Bullock and Tilley 2003; Thornberry et al. 2003).

Being a gang situated within what Densley (2012) would coin the recreational stage, YSGs are overly concerned with issues of territoriality and visible displays of protest masculinities as a way to obtain what Anderson (1999:34) terms 'street credit'. These factors steer YSGs behaviour. This is primarily due to YSG members being too young and developmentally immature to successfully earn, or participate in earning, economic capital through criminal venture (VRU 2011). As a consequence, status is achieved through the display of protest masculinities within peer groupings which consist of a small number of persistent offenders, which the author terms core members, and a larger loose association of individuals whom drift in an out of affiliation, often to break mundane lifestyles in deprived communities (Matza 1964). The author terms the latter the outer layer. While contemporary academic literature regarding Scottish gangs does not directly outline differences within the group such distinction is vaguely referred to within a number of studies (Deuchar et al. 2015; Patrick 1973). Drawing upon Vigil's (1988) study of US Barrios gangs, Miller (2015) suggests YSGs are not so much gangs as opposed to loose peer groups centred upon aspects of street socialisation whereby local scheme identity becomes intertwined with group identity. This idea of the gang being bound to territorial surroundings is a recurring theme in contemporary Scottish gang literature (Deuchar 2013; Holligan and Deuchar 2009). Adopting a Bourdieuian approach to gang studies both Deuchar (2009), and Fraser (2013) similarly argue that youths involved in YSGs do so in order to acquire social capital and gain local status through tough masculinities (Lawson 2013). Often a by-product of 
territorial violence is weapon carrying. McAra and McVie (2010) argue that such behaviour primarily occurs for reasons related to masculine status, yet Holligan et al. (2016) suggest fearful perceptions of knife carrying gangs, presented in the media and local narratives, to be self-perpetuating, whereby weapon carrying occurs primarily for self-defensive purposes.

Yet the way in which the Scottish YSG is perceived has changed over time. Given that there remains little academic study of Scotland's gangs prior to the Second World War, the author focus on literature relating to Glasgow gangs. This is because the city has a long and synonymous history of gangs that can be traced back to the infamous razor gangs of the 1920s/30s (Davies 2007). Glasgow's gangs were forged in sectarian division following mass immigration of Irish Catholics into industrialising Glasgow. Many migrant settlements ran adjacent to indigenous, and predominantly Protestant, communities. The resulting territorial conflicts were very much steeped in sectarian hatred (Davies 2013). Yet, while the gang was territorially based, it was also frequently engaged in OC. Bartie $(2010,2014)$ and Davies $(1998,2007)$ both draw attention to the fact that, in a society existing prior to advanced globalisation, Glasgow gangs regularly participated in crime-for-profit activities including racketeering, extortion, and jewellery heists. This is supported by a number of autobiographical accounts (Boyle 1977; Sillitoe 1956). However, while the razor gang is recognised as being both territorial and engaged in OC, contemporary YSGs are not. The author argues that, following the demise of the razor gang, contemporary youths undergoing street socialisation adopt the local intergenerational narratives passed on by older ex-gang members. These youths attempt to relive the glory days of the gang and likewise gain status. The glamorization of these somewhat fictional narratives concerning gang activities has led to the emphasising of certain assumed gang traits over others. Nowhere has this been more evident in the trait of territoriality (Kintra et al. 2008). Youths 
lacking the developmental capacity to engage in OC emphasize those traits more accessible to them such as territoriality and violence.

\section{Assumed Gang History: Influencing Gang Studies}

The emphasizing of certain gang traits over others, i.e. territoriality over OC, has resulted in YSGs being both visible as well as self-labelling. Thus, despite retaining many identifiable features with SOCGs, academic research in Scotland has become overly focused upon the gang at its recreational beginning to the detriment of other gang typologies. So why has this occurred? While a full account of how YSGs have come to be overly fixated upon is beyond the scope of this paper (Mclean, Forthcoming), this can largely be attributed to two main factors. One is the conventional wisdom of gang research and the other is the issue of selflabelling. Firstly, concerning the conventional wisdom of gang research the researcher is required to identify the gang per se. Given its popularity in providing a workable European relevant definition researchers often turn attention to Klein's (2001) Eurogang definition which states the gang to be "any denotable adolescent group of youngsters who (a) are generally perceived as a distinct aggregation by others in their neighbourhood, (b) recognize themselves as a denotable group - almost invariably with a group name -, and (c) have been involved in a sufficient number of delinquent incidents to call forth a consistent negative response from neighbourhood residents and/or law enforcement agencies" (p. 428). By analysing this definition, we can see that the traits of youth, visibility, and self-labelling are emphasized as key components. Therefore, within a Scottish context, when researchers seek the gang, typically adhering to such definitions, they find it in YSGs as due to being youthful are also very visible, and likewise retain self-labelling properties.

This brings us to the second point of self-labelling. Being labelled a gang only goes so far in identifying the gang; this is evident in the way a number of organisations have at times been 
referred to as a gang or operating like a gang. This has included the police force, large cooperation's, or even political groups, which have all at some stage been referred to as 'gangs' (Hallsworth and Brotherton 2011; Hallsworth and Young 2008). Yet these terms have ultimately failed to adhere over time. This is primarily due to two reasons. Firstly, such groups have the power to reject labels and refute them publicly. Secondly, such groups do not wish to be coined 'a gang' as it has a negative effect on the organisation's operations and therefore these groups do not self-label themselves as a gang (McHoul and Grace 2015). However, this is not the case with YSGs. They are both labelled, and wish to be labelled, as gangs. This self-labelling is primarily due to issues of street socialisation, local narratives, and status seeking (Fraser 2013; Miller 2015). Therefore, when researchers ask such visible youth groups if they are the local gang, retain gang affiliations, or associate with gang members, more often than not the reply is yes. This is evident also in the Edinburgh Youth Studies, which sought to identify the extent of gang membership amongst young adolescents in the city. Research findings identified that a significant amount of youths labelled themselves as gang members - or having gang affiliations - yet this number decreased significantly with age. Similarly, gang membership was intertwined with street socialisation and scheme identity (McAra and McVie 2010; Miller 2015). Arguably, these self-labelling properties are thought of as immature by mid to late adolescents and thus selflabelling practices decline with age development. Thus, when combined with the fact that offenders engaged in OC typically a) wish their actions to primarily remain covert, b) no longer adhere to being visible, and c) are considered distinct from YSGs by official authorities, then those YSGs which evolve towards criminality often do so undetected. Rather, no affiliation between contemporary YSGs and OC is recognised in Scotland, either at an official level or by academics. Yet the findings presented in this article suggest otherwise. 


\section{Methodology}

Following a review of the literature, a significant gap was identified in relation to the organising properties of Scotland's YSGs. Primary data presented in this article was collected between 2013 and 2016 as part of a qualitative inquiry investigating the possibility that gang organisation serves as a means to gang business. Given that Glasgow, Scotland's largest city, has a prevalent and historically embedded gang culture (Davies 2013; Deuchar 2013; Miller 2015), in addition to disproportionately retaining the vast majority (70\%) of Scotland's OC, $65 \%$ of which is directly related to illegal drug supply, it proved the ideal location for conducting such a study. While a full scale gang revisiting has been underway in an Anglo-Welsh context over the past decade (Densley 2012; Pitts 2012), this has not been the case in Scotland. Instead, Scottish gang literature has become overly focused upon the recreational outfits of YSGs involved in territorial conflicts with similar outfits. Violence is almost random almost, and tends to be linked to issues of status. Although the VRU (2011) does not have a specific YSG definition, they are nonetheless described as young territorial outfits engaged in violence which at times involves weapon use, and in particular knife use. YSGs are ultimately considered distinct from OC. Instead OC is thought to be carried out by SOCGs. These are defined in the Scottish Government, 2015, report 'Scotland Serious and Organised Crime Strategy' (SSOCS) as follows: “a) involve more than one person, b) is organised, meaning that it involves control, planning and use of specialist resources, c) causes, or has the potential to cause, significant harm, and d) involves benefit to the individuals concerned, particularly financial gain" (Scottish Government 2015:6). In Scotland YSGs and OC are thought to share no correlation. In seeking to investigate the potential for gang organisation as a means for gang business the author outlined participant criteria as; 
a) Participants must have experience of group offending

b) Participants must have been involved in behaviour outlined by the 2015 SSOCS report as Serious and Organised Crime

c) Participants must be over 16 years of age.

To help access participants, street workers attached to key youth outreach projects in the West Coast of Scotland were used as initial gatekeepers. As a result of difficulties associated with accessing hard to reach populations, given participation in (re)offending, a snowball sampling technique via gatekeepers was used to access wider sample populations (Bhopal and Deuchar 2016). Becker (1963) suggests this is relevant where sampling frame is limited. Accordingly, street workers and interviewed participants were asked to recommend additional contacts who met the set criteria and would potentially consider participation in the research.

In-depth interviews were conducted with participants $(n=35)$ who met the criteria. All participants, with the exception of one, were male. All participants considered themselves indigenous, although not all were white. All considered themselves to have been raised in deprived working-class neighbourhoods situated within the greater Glasgow conurbation (Scottish Government 2012). Most participants came from re-ordered families (Roger 2008). Ages ranged from $16-27$. These interviews enabled the researcher to gain insights into the way participants understood certain events or situations. Deploying open-ended interview techniques allows interviewees to convey, without restriction, their distinct subjective experience of their role within gang organisation as a means for gang business. Efforts were undertaken to keep interview questions as open as possible in order to allow the researcher be responsive to emerging data. Extracts chosen illustrate interviewees' personal construction of reality through their own voices. Multiple interviews were scheduled 
whenever possible, ranging between 1 to 5 interviews with each participant. Interviews lasted approximately 1 hour on average. Almost all interviews were conducted on a one-toone basis, although two interviews were group interviews ( $n=4$ and 5). Data was triangulated whenever possible, typically with youth workers or other interviewees. Data was recorded via audio devices and then analysed thematically (Creswell 1998). Interview locations were chosen by participants and not the researcher in order to make the interviewees feel as relaxed and comfortable as possible, particularly given the nature of that being discussed i.e. participation in delinquency and OC. Due to the fact that participants were accessed via voluntary organisations and snowball sampling techniques Enhanced Disclosures were not required. Ethical approval was granted by the researcher's home institution. Prior to interviews, an information sheet outlining relevant information was distributed, alongside a volunteer sheet that participants were required to sign. General research questions covered the following issues: has the participant ever been involved in gangs? How did the participants become involved in serious and organised crime? What role did YSGs play in this process, if any? What does serious and OC look like in Scotland?

\section{Findings}

The results emerging from the data analysis are represented thematically. The two overarching themes are: 'Gang Organisation 'and 'Gang Business'. The selected extracts are taken from interview transcripts. Names are pseudonyms and are replaced with names of fictitious characters from Marvel Comics.

\section{Gang Organisation}


Gang organisation refers to the ability of a gang to organise itself in response to external conditions (Densley 2012). These conditions come in a variety of forms. Yet this research focuses on several key conditions, namely external threats, maturity, and financial commitments. Klein (1971) argues that group solidarity and cohesion are often the natural response to external conditions which prove threatening. Quinn (2001) similarly suggests external tensions may serve to increase the likelihood that groups will engage in serious forms of criminality. This can result in loose recreational peer groups consolidating and being formed into hardened gangs (Hallsworth and Young 2006; Hagedorn 1988). In both the US and the UK, a key concern surrounding gang organisation and proliferation has been the tendency of gangs to become involved in more serious and organised forms of crime. This in turn may lead to greater levels of violence (Miller 2000). As previously stated within the article this process has been analysed considerably in an Anglo-Welsh context, but not so in Scotland, where the focus has been upon the gang in its recreational stage. The gang has not been examined beyond this stage; whereby the gang moves towards incorporating criminality as an integral group feature. While the YSGs is very much recreational in its purpose as members mature and enter their later adolescent years those core members form greater levels of solidarity while also disassociating with those of the outer layer whom often cease offending altogether. As core members consider criminality to be intrinsic to their own personal characteristics, this process sees core members gradually become disproportionately associated with likeminded criminals who advocate criminal practice as acceptable behaviour (Sutherland 1947). Former YSG core member Cyclopes describes this process;

'Get older and just drift away from most people (the outer layer) you use to hang about with don't you. Different people, suppose. Most of my old mates pure got jobs and that after leaving school... [I] still hung around with my best mate, me and [name censored], we 
always hung about. We are kind of like each other you know, like the same things and that. Always pure have. Always got into trouble together (laughs).... ended up working together (selling drugs) aye.... [Even] got the jail together. Can pure trust him' - Cyclopes

Having been core members of a local YSG, Cyclopes and his friend gradually relegated friendships with those of the outer layer to a secondary position. This process led Cyclopes and his friend to form a greater sense of cohesion based upon shared criminal identity. This process was further aided by natural maturity, as well as the perceived threats from external sources as Cyclopes elaborates upon;

'I only hang about way him (Cyclopes friend). Got pure closer you know. You go through things and [it] bonds you, aye. Pure makes you like closer, if that makes sense? No gay like, but like pure good mates... police and that [rival gang] were pure after us as well, after we had got into a bit of trouble. [censored name] ended up just living way me (laughs). Basically.' - Cyclopes

As illustrated in Cyclopes statement, the presence of an external threat brought a close friendship even closer as gang members bound together for protection, perhaps also by a sense of only being able to trust one another. Being older and having access to their own economic capital and living accommodation also allowed this process to occur. This is often something lacking in YSGs whom have neither their own economic capital nor their own accommodation and therefore cannot break with parental authorities (Hazani 1986). Due to their age most are restricted from such resources and rely solely on parental figures for both income and accommodation. Decker and Van Winkle (1996) also draw attention to the fact that many gang members are too young to successfully engage in OC. It is only with maturity that gang members are able to gain access to the required resources necessary for 
both independence and participation in OC. Hagedorn (1994) also points out that even when youths whom consider their own identity to be intrinsically criminal do engage in crime-forprofit activities more often than not such behaviour is self-motivated and independent of group processes. Like Cyclopes, Beast also outlines a process which saw both himself and close friends move away from the recreational YSG and incorporate criminality into group identity. Yet, reflecting upon this procedure, Beast recognises that during his time spent in the YSG he was too young to successfully engage in OC even when making efforts to do so.

When you're in school [we] use hang about in big numbers.... always ends up in fights [with rival YSGs] .... You get older the groups get [smaller]... You think you're like the big man when your wee (young) but you aren't. [you are] just a daft wee boy. I didn't start dealing proper till I was older. I tried when I was 14 or something. Maybe 15, don't know. Can't remember. Was pure young but. Pure too stupid to do it. Taking swedgers (Ecstasy tablets) and falling about the streets. Giving them away, to mates, giving them for fuck all. No joke bud, think you lose more than you make [at that age]' - (Beast)

Beast recognised that with age comes a more refined mental capacity capable of engaging in OC. At a younger age Beast lacked the self-control necessary to sell illegal commodities at a profit. Yet with age Beast was able to participate in this type of behaviour much more effectively. The study found that growing older regularly resulted in the vast majority of YSG members desisting from crime and delinquency. This is primarily attributed to their engagement in the adult world of work, parenthood, and other financial commitments. However, typically those members who did desist from crime, through the natural ageing process, belonged to the YSG outer layer. While core members were also presented with these same pressures of adulthood, crime was perceived as a mechanism for resolving such commitments. Adulthood might have brought with it more responsibilities and 
commitments, but likewise adulthood also provided greater opportunity to engage in crimefor-profit activities. Crime was essentially seen as a potential occupation in itself. Being predisposition towards crime meant that participation in crime was often driven by a substantial degree of rationality, albeit often in circumstances with limited choice (Lindegaard and Jacques 2014).

Wolverine typifies the core member. At a young age Wolverine sought local status through participation in territorial violence, however this same participation ultimately led to him acquiring a criminal record. He has since struggled to gain legitimate employment. Nonetheless Wolverine is by no means exempt from the pressures of living in a consumer society which demands his participation, even though he is assigned to the economic scrapheap. Wolverine details how this process saw him render himself forever a criminal and use former YSG connections to participate in gang business;

'I didn't have an education and couldn't get a job, my record was too bad. A had no choice but to try and sell. You only want what everyone else does don't you! Be comfortable and provide your kids way the stuff you didn't have' - Wolverine

Wolverine's behaviour as a youth limited his options as he grew older. When he reached adulthood and wished to engage in the legitimate employment of his choice he was unable to do so. Met with such strain, Wolverine quickly conclude that he had 'no choice' but to engage in criminal coping strategies (Agnew 2013). Like other participants in the study, Wolverine organised core members of the local YSG in order to engage in gang business, i.e. typically drug dealing. The gang effectively evolved in many respects and ceased to be a recreational outfit and instead progressed towards criminality. As a consequence, these core members had to effectively resign YSG membership. This is because YSG involvement is 
centred around issues of territoriality. However, successful drug supply requires a fluid market space, transcending territorial boundaries. Effectively these former YSG members resigned YSG membership and instead evolved into small groups which, while formed primarily for social purposes, nonetheless centre social relationships upon criminality and shared criminal identity (Mares 1999). At the criminal stage the gang holds criminality to be intrinsic to group identity and group activity.

\section{$\underline{\text { Gang Business }}$}

As gangs organise they typically do so in response to external threats or pressures (Klein 1971). Effectively the gang becomes a way for members to relieve such pressures or reduce threat levels. Consequently, as YSG members age and become more developmentally and physically mature, they are also able to partake more successfully in criminal ventures. In its recreational stage the YSG comprises mainly of youths in their early to mid-adolescent years, and this has an impact upon gang ability to conduct gang business effectively (Decker and Van Winkle 1996; Hagedorn 1994). As the majority of YSG members drift in and out of gang affiliation, YSGs essentially lack the unified group identity, adhering to intrinsic criminality, required for particularly organised gang behaviour (De Motte 1984). In addition, those YSG members that do retain criminality as intrinsic to their own identity lack the physical and mental stature required for successfully disposing of, or challenging, existing adult groups involved in OC. Yet as YSG members age, and solidify around those smaller numbers of individuals whom share an intrinsic sense of criminality, they are also able to organise gang behaviour more effectively (Densley 2012). Coupled with the natural ageing process, other factors such as financial commitments and external threats - in the form of intervention agencies, police, or other gangs - sees members further solidify and tap into criminal networks in order to engage the gang in criminal business as a way to relieve strain 
(Agnew 2013). Fader (2016) describes how criminal networks are typically accessed via criminal familial relationships or extended networks of kinship. This is primarily due to issues of trust. Gang business was found to primarily take the form of drug dealing as emphasized by Gambit;

‘loads a people do it (sell drugs). You need to now. No jobs, you know what am saying pal? Like, it's not like the old days when you could just go out and get a jobs. Employers are always wanting to see qualifications now aren't they? Most guys I know don't have that (qualifications). What else am I meant to do? No like I've much choice you know; you need to money to buy stuff... [and] it's all pure expensive now.' - Gambit

As with Wolverine, feelings of being left behind in an advanced capitalist society which on the one hand demands participation in consumer society yet on the other hand simultaneously fails to provide steady and reliable means for legitimately doing so, saw former YSG member Gambit turn to selling drugs with two of his closest friends (also former YSG members). Ultimately, having once retained membership in a local YSG has enabled Gambit to engage in consumer society through criminal venture by organising the gang around other members who also deem criminality to be intrinsic to their own identity. Yet what does such criminal behaviour actually look like upon closer inspection? In order to analyse gang business in greater detail the author draws upon Coope and Bland's (2004) hierarchical three tier model of Scotland's illegal drug market. This model is a three tier pyramid structure consisting of international, middle, and retail-level dealerships. However, as McPhee (2013) notes, lines of business between levels and specific roles within each level are anything but clear. While the author failed to access those operating the hierarchy apex at international level, participants considering themselves to occupy the middle and retaillevels provided overviews of market structures and process; 
'Not everyone can import stuff... I've only met them bringing the stuff in, but they won't be the actual guys arranging the smuggling [from outside the UK]. They are like representatives [in the UK], obviously working for [traffickers outside the UK]. Probably [extended] family or something... They (the importers) sell large to a few guys who [then] move it on to people who sell it in smaller bulks or [initial UK buyers even sell small amounts over a considerable duration] .... not everyone [of the initial UK buyers] would buy the same amount.... depends.' (Sabretooth)

Although Sabretooth's claims concur with Coope and Bland's (2004) pyramid model, market levels are perhaps substantially more fluid and less clearly defined and occasionally incorporating various sub-levels of supply between those three identified tiers. Arguably, the market demonstrates tremendous flexibility to adjust accordingly upon those dependant circumstances. Sabretooth suggests market levels may overlap and are by no means fixed or static. The precise level of supply in which gangs engage in seems to vary significantly and will often depend upon group experience. As the gang evolves towards the criminal stage it may initially dabble in primarily retail-level drug supply, yet as they gang grows more confident and establishes more criminal contacts, the amount of drugs supplied will also increase. Magneto details this process;

'You work with your pals... [you] can trust them to do business way. You can't just [initially] start of like big time gangsters (laughs). Really start by selling weed, aye. Well we did, aye. Me and [censored name]. Sold weed to wee guys first. Done a few grows, you know, a few pots in the cupboard. That stuff. It is not really that hi-tech to be honest mate.... [as the gang progresses in experience] you'd chip in a couple a G[rand] to buy big (now purchasing cocaine). Cut and sell in [smaller] packages.... doesn't happen like every other day or nothing. 
Sometimes this kind of thing comes in, other times it doesn't.... that's when you end up selling to people you know, say wee grams here and there, shit like that fella.' (Magneto)

Magneto draws attention to the ways in which, alongside trusted friends, he initially sold class $\mathrm{C}$ drugs to local youths. However, as the gang continued to evolve and thus grow in confidence, experience, and reputation, the gang gradually engaged in a greater degree of criminality. Eventually the gang was successful enough to purchase large quantities of class A drugs for resale. By organising the gang and drawing upon combined resources, members were able to conduct successful gang business. In addition, Magneto illustrates how drug dealing had, in effect, become intrinsic to group identity as they strategically negotiated various levels of the illegal drugs market. McPhee (2013) similarly found that social supply dealers often progressed towards greater involvement in drug distortion with time and experience. Storm outlines how his gang also became more involved in drug distribution;

'Started selling about fifteen. Initially Eccie's (Ecstasy tablets) because we use to take them.... It wasn't really planned at first. My pal knew a guy who done pure good gear (cocaine) man so got some and a few of us just sold it for this guy, who was a so-called gangster, supposedly, he was an older cunt. We got a cut for mostly selling to other people we hung about way at the shops... after a while, we thought fuck it cut him out. He's not doing the work... went right to [the source] .... if you don't want cut out, don't tell who your source is' - (Storm)

Storm and his gang were able to organise more effectively as they gained greater access to the drugs market. Ultimately gang organisation and gang business can only progress in conjunction with one another. Furthermore, as Storm points out, there is significant lack of trust within the criminal underworld where disputes cannot be settled by third party law. It would seem that, combined with the ability to draw together resources, the lack of 
trustworthiness influences criminals to work together in groups. Yet these groups also satisfy a social need also whereby members can share experiences and retain friendships while still generating income. The participants rarely, if at all, referred to fellow gang members as partners but rather as friends. This is an aspect all too often overlooked within the current gang revisiting.

\section{Discussion}

The revisiting of the British gang has sought to establish whether or not UK gangs are organising, becoming increasingly criminal, and proliferating across the country. There has been growing support to suggest that this may be the case within an Anglo-Welsh context. However, as previously mentioned, in Scotland the gang revisiting has failed to progress beyond those groups situated within the recreational stage of development, i.e. the YSG. Yet this article has presented qualitative evidence that YSGs in Scotland do not only possess the potential and capability to evolve but are making conscious efforts to do so. The findings relating to gang organisation demonstrate that Scotland's YSGs typically organise in response to naturally developing maturity and the presence of external threats or pressures. However, the ability to organise effectively can only occur in conjunction with those activities which are tailor made for the gang. In Scotland, as in the US, this usually means illegal drug distribution. Gangs have only been able to organise effectively because illegal drugs have become more readily available and drug markets accessible. Alonso (2004) describes how, with the rise of globalisation, the free market, and improved transport, the gang has proved the perfect outlet for drug distribution for transnational drug smugglers. Scotland has by no means been exempt from those complex processes apropos globalisation which have seen illegal commodities and methods of distribution become ever more readily 
accessible. While, in previous decades, access to such criminal networks required preexisting connections, in the contemporary era this is not the case. The age of technology has rendered such requirements largely obsolete. The gang can now control its own destiny and actively seek to engage in such criminal ventures without much prior knowledge of the illegal market. The participants in the study draw attention to the fact that legitimate participation in consumer society was unobtainable for them. Yet drug distribution allows those at the bottom of the economic scrapheap, as most participants resided within Scotland's most deprived areas, to actively re-engage in society once more. This process is one which may well intensify with continued welfare retrenchment and benefit cuts.

However, a deeper consequence of the gang revisiting may well be the political knee jerk reaction it has caused (Hallsworth and Brotherton 2011). As Klein (1971) suggest, such unwarranted attention may actually serve to bring about gang cohesion. Creating a gang model from which law enforcement can work, Hallsworth and Young (2006) build upon Klein's concepts and point out that properly identifying the gang will help those who seek to intervene to do so effectively without proving to be counterproductive. Furthermore, the scholars also highlight the problem in not being tough enough on those groups which are involved in OC. If such groups are approached in a laissez-faire manner, then not only will the group remain firmly intact but gang behaviour will remain undeterred. In Scotland, the lack of identified gang typologies has led to a) YSGs continuing to remain prevalent throughout Scotland's most deprived communities, and b) the criminalisation of those youths that are on the fringes of OC. Classifying such individuals as belonging to OC networks only serves to label and further embed criminal identity. Thus this article does not only seek to identify the existence of gangs organising for gang business in Scotland but to also prove a model on which future research can built given that the gang in its recreational stage has been disproportionately analysed. 
Having revised the data and outlined those process which have enabled Scotland YSGs greater potential to evolve, the author now attempts to bridge the existing gap in literature that failed to establish relationships between YSGs and OC, by presenting an evolving gang model as applicable in a Scottish context (See Figure 1). The model emphasizes that gangs exist on an evolving continuum as opposed to an either-or status. Bolden (2012) also points out that levels of gang involvement are in reality fluid and often a far cry from the simplistic member/non-member models with which we are regularly presented with by law enforcement. The presented model outlines how YSGs are predominantly recreational outfits whereby youths that share local history, proximity, and existing friendships associate in loose peer groups. While the YSG is at times delinquent it is nonetheless far from being inherently criminal. Cobbina et al. (2010) also highlight this point and suggest that delinquency and even violence carried out by male and female urban youth groups alike typically revolves around issues of status achievement and recreation as opposed to outright criminality. In the recreational stage the gang retains the potential to evolve towards criminality. The author coins the gang at the criminal stage Young Crime Gangs (YCG) in an effort to capture both their ongoing physical and mental development and also the nature of group identity. Typically, YCGs are compromised predominantly of those core members who participated in the vast majority of YSGs criminal activity (Deuchar et al. 2015). These members will break away from the larger and more fluid YSG and instead begin to solidify and become more cohesive. This process occurs in response to both natural maturities associated with the ageing process and the introduction of external threats or pressures. As criminality is intrinsic to such individuals own personality, it consequently becomes an integral feature of wider YCG identity. This procedure is aided by disproportionate delinquent association (De Coster and Heimer 2001). Due to the fact that criminality, as opposed to general delinquency, is central to YCG behaviour, the gang makes a crucial 
break here from YSGs. In attempting to engage in OC YCGs are no longer territorial in nature.

Kintra et al (2008) points out that in Scotland, and particularly in Glasgow, territorial boundaries can be as little as a few streets. Thus if YCGs retained territoriality as integral to gang characteristics then the range they have over potential customers may prove inadequate for significant financial profits. However, while YCGs engage in OC, or crime that is organised, gang existence is primarily for social purposes (Mares 1999). The gang's criminal activities are a consequence, or by-product, of group existence. Ultimately gang activities are hybrid in nature and lie between the social and economic factors. Yet, as YCGs continue to engage successfully in increasingly serious and $\mathrm{OC}$, eventually the purpose for group existence undergoes a drastic change. As members become adults and financial gains increase then the purpose for group existence becomes one of purely business. Membership may expand at this stage to incorporate wider criminal partnerships. At this stage the YCG has effectively become a SOCG and thus enters into the syndicate stage of the provided model. El Sayed et al. (2016) point out that persistent adult offending is typically a sequential process following on from prior offending patterns in late adolescence. Repeat and continued offending is very much a progression. Yet it is important to note that not all YSGs will evolve into YCGs. Nor is it a given that YCGs will evolve into SOCGs. Rather, gang evolution is a potential and requires not only the right blend of individuals being brought together but also the right conditions. Furthermore, YCG duration is more often than not short lived given that members are still gaining those criminal skills necessary for successful engagement in OC. Therefore, members will often fail to carry out such criminal ventures successfully. This can lead to not only apprehension by law enforcement but also being put out of business by more evolved gangs. Essentially YCGs face multiple obstacles including those from within the gang itself. YCG members typically retain a sense of 
omnipotence and hyper-masculinity (Hallsworth and Young 2004). Pride and hypermasculine identity can also lead to YCG members becoming involved in other criminal activities which are counterproductive to OC, such as violence, intoxication, or taking increasing risks with drug supply and distribution. These factors can prove detrimental to overall group cohesion, particularly once financial gains become substantial.

\section{References}

Agnew, Robert. 2013. "When Criminal Coping is Likely: An Extension of General Strain Theory". Deviant Behavior 34: 653-670

Aldridge, Judith., Medina, Juango and Ralphs, Robert. 2008. “Dangers and Problems of doing Gang Research in the UK". Pp.31-46 in Street Gangs, Migration and Ethnicity, edited by F. V. Gemart, D. Peterson and L. Inger-Lise. Devon: Willan Publishing

Alonso, Alejandro A. 2004. “Racialized Identities and the Formation of Black Gangs in Los Angeles". Urban Geography 25(7): 658-674.

Anderson, Elijah. 1999. Code of the Street. New York: W. W. Norton.

Bartie, Angela. 2010. “Moral Panics and Glasgow Gangs: exploring the New Wave io Glasgow Hooliganism, 1965-1970". Contemporary British History 24(3): 385- 408.

Becker, Howard. 1963. Outsiders. New York: Free Press. 
Bennett, Trevor. and Holloway, Kate. 2004. "Gang Membership, Drugs and Crime in the UK". British Journal of Criminology 44(3): 305-323.

Bhopal, Kalwant. and Deuchar, Ross. 2016. Researching Marginalized Groups. New York: Routledge.

Bolden, Christian L. 2012. "Liquid Soldiers: Fluidity and Gang Membership". Deviant Behavior 33: $207-222$.

Bullock, Karen. and Tilley, Nicolas. 2003. Crime Reduction and Problem-oriented Policing. Devon: Willian Publishing

Boyle, James. 1977. A Sense of Freedom. London: Pan Books.

Campbell, Anne. and Muncer, Steven. 1989. “Them and Us: A Comparison of the Cultural Context of American Gangs and British Subcultures". Deviant Behavior 10: 271-288.

Cobbina, Jennifer E. Like-Haislap, Toya Z. and Miller, Jody. 2010. “Gang Fights versus Cat Fights: Urban Young Men's Gendered Narratives of Violence". Deviant Behavior 31: 596-624.

Coope, Samantha. and Bland, Nick. 2004. Reducing the Impact of Local Drug Markets: A Research Review. Edinburgh: Scottish Executive.

Creswell, John W. 1998. Research Design: Qualitative, Quantitative, and Mixed Methods Approaches. 2nd ed. Thousand Oaks, CA: Sage. 
Davies, Andrew. 1998. "Street Gangs, Crime and Policing in Glasgow during the 1930s: The Case of the Beehive Boys". Social History 23(3): 3-4.

Davies, Andrew. 2007. “The Scottish Chicago? From Hooligans to Glasgow in the Late 1920's". Cultural and Social History 4(4): 511-527.

Davies Andrew. 2013. City of Gangs: Glasgow and the Rise of the British Gangster. London: Hodder and Stoughton.

De Coster, Stacey. and Heimer, Karen. 2001. “The Relationship Between Law Violation and Depression". Journal of Criminology 39(4): 799-836.

De Motte, Charles. 1984. “Conflicting Worlds of Meaning: Juvenile delinquency in 19th Century Manchester". Deviant Behavior 5: 193-215.

Decker, Scott H. and Barrik Van Winkle. 1996. Life in the Gang. Cambridge, England: Cambridge University Press

Densley, James A. 2012. “The Organisation of London's Street Gangs”. Global Crime 13(1): $42-64$.

Densley, James A. 2013. How Gangs Work: An Ethnography of Youth Violence. London: Palgrave Macmillan.

Deuchar, Ross. 2009. Gangs, Marginalised Youth and Social Capital. Stoke-on-Trent: Trentham Books. 
Deuchar, Ross. 2013. Policing Youth Violence: Transatlantic Connections. London: Trentham Books/IOE Press.

Deuchar, Ross. Miller, Johanne. and Barrow, Mark. 2015. “Breaking Down Barriers with the Usual Suspects: Findings from a Research-informed Intervention with Police, Young People and Residents in the West of Scotland". Youth Justice 15(1): 57-75.

Downes, David. M. (1966). The Delinquent Solution. London: Routledge and Kegan Paul.

El Sayed, Sarah A. Pacheco, Daniel F. and Morris, Robert G. 2016. “The Link between Onset Age and Adult Offending: The Role of Developmental Profiles". Deviant Behavior 37(9): 9891002.

Fader, Jamie J. 2016. “Criminal Family Networks: Criminal Capital and Cost Avoidance among Urban Drug Sellers". Deviant Behavior 37(11): 1325-1340.

Farrington David P, Coid JW and Murray J. 2009. “Family Factors in the Intergenerational Transmission of Offending". Criminal Behaviour and Mental Health 19(2): 109-124.

McHoul, Alec. And Grace, Wendy. 2015. A Foucault Primer: Discourse, Power and the Subject. New York: Routledge.

Fraser, Alistair. 2013. "Street Habitus: Gangs, Territorialism and Social Change in Glasgow". Journal of Youth Studies 16(8): 970-985. 
Kintrea, Keith. Bannister, Jonathan. Pickering, Jonathan. and Reid, Margret. 2008. Young People and Territoriality in British Cities. York: Joseph Rowntree Foundation

Klein, Melanie W. 1971. Street Gangs and Street Workers. Englewood Cliffs, NJ: Prentice Hall. Klein, Melanie W. 2001. The Eurogang Paradox: Street Gangs and Youth Groups in the U.S. and Europe. 1st Ed. California: Springer.

Lawson, Robert. 2013. “The Construction of ‘Tough' Masculinity: Negotiation, Alignment and Rejection." Gender and Language 7(3): 369-395.

Lindegaard, Marie R. and Jacques, Scott. 2014. "Agency as a Cause of Crime". Deviant Behavior 35: $85-100$

Hallsworth, Simon. 2013. The Gang \& Beyond: Interpreting Violent Street Worlds. London Palgrave McMillan.

Hallsworth, Simon. 2014. “Gang Talking Criminologists: A Rejoinder to John Pitts". Youth and Policy 112: 35-43

Hallsworth, Simon. and Brotherton, David. 2011. Urban Disorder and Gangs: A Critique and a Warning. London: Runnymede.

Hallsworth, Simon and Young, Tara. 2004. "Getting Real About Gangs". Criminal Justice Matters 55: 12-13. 
Hallsworth, Simon. and Young, Tara. 2006. Urban Collectives: Gangs and other Groups. Report for Operation Cruise. London: HM Government/Metropolitan Police.

Hallsworth, Simon. and Young, Tara. 2008. "Gang Talk and Gang Talkers: A Critique". Crime, Media Culture 4 (2): 175-195.

Harding, Simon. 2014. The Street Casino: Survival in Violent Street Gangs. Bristol: Policy Press

Hagedorn, John M. 1994. “Neighbourhoods, Markets and Gang Drug Organization”. Journal of Research in Crime and Delinquency 31: 264-294.

Hagedorn, John M. 1998. People and Folks: Gangs, Crime and the Underclass in a Rustbelt City, Chicago: Washington, DC: Lakeview Press.

Hazani, Moshe. 1986. “A Path to Deviance: A Multi-stage Process”. Deviant Behavior 7: 159174.

Holligan, Chris. and Deuchar, Ross. 2009. “Territorialities in Scotland: Perceptions of Young People in Scotland". Journal of Youth Studies 12 (6): 727-742.

HM Government. 2011. Ending Gang and Youth Violence: A Cross-Government Report including Further Evidence and Good Practice Case Studies. London: Home Office.

Holligan, Chris. McLean, Robert. and Deuchar, Ross. 2016. “'Don't You Know Glasgow's the Sab Capital of the World?' Understanding the Narratives about Weapon Carrying Among Working-Class Teenage Boys in Glasgow." Critical Criminology: An International Journal. DOI 10.1007/s10612-016-9336. 
Mares, Dennis. 1999. “Globalization and Gangs: The Manchester Case.” Focaal 35: 135-155.

Matza, David. 1964. Delinquency and Drift. New Jersey: Prentice-Hall.

McAra, Lesley. and McVie, Susan. 2010. Youth Crime and Justice: Key Messages from the Edinburgh Study of Youth Transitions and Crime. Criminology and Criminal Justice. 1-32

McLean, Robert. (Forthcoming). Discovering Young Crime Gangs in Glasgow: Street gang Organisation as a Means for Gang Business. Unpublished Thesis.

McPhee, Iain. 2013. The Intentionally Unseen: Illicit \& Illegal Drug use in Scotland. Saarbrucken, Germany: Lambert Academic Publishing

Miller, Johanne. 2015. In Every Scheme there is a Team: A Grounded Theory of how Young People Grow in and out of Gangs in Glasgow. Unpublished Thesis.

Miller, Walter B. 2000. The Growth of Young Gang Problems in the United States: 1970-98. Washington DC: US Department of Justice.

National Crime Agency. 2013. Serious and Organised Crime Strategy. London: Home Office/HM Government.

Patrick, James. 1973. A Glasgow Gang Observed. Wiltshire: Redwood Press. 
Pitts, John. 2008. Reluctant Gangsters: The Changing Face of Youth Crime. Devon: Willan Publishing,

Pitts, John. 2012. Reluctant Criminologists: Criminology, Ideology and the Violent Youth Gang. Youth Policy, 109: 27-45.

Quinn, James F. 2001. “Angels, Bandidos, Outlaws, and Pagans: The Evolution of Organized Crime among the Big Four 1\% Motorcycle Clubs". Deviant Behavior 22: 379-399.

Roger, John J. 2008. Criminalising Social Policy: Anti-social Behaviour and Welfare in a Decivilized Society. Devon: Willian Publishing

Scottish Government. 2009. Let our Communities Flourish. Edinburgh: Scottish Government.

Scottish Government. 2012. Scottish Index of Multiple Deprivation. Edinburgh: Scottish Government.

Scottish Government. 2015. Scotland Serious Organised Crime Strategy Report. Edinburgh: Scottish Government

Sillitoe, Percy Sir. 1956. Cloak without Dagger. London: Pan.

Sutherland, Edwin H. 1947. Principles of Criminology. 4th ed. Philidelphia: Lippincott. 
Thornberry, Terence P., Marvin D. Krohn., Lizotte, Alan J., Smith, Carolyn A., and Tobin, Kimberly. 2003. Gangs and Delinquency in Developmental Perspective. Cambridge, England: Cambridge University Press.

Vigil, James D. 1988. Barrio Gangs: Street Life and Identity in Southern California. Austin TX: University Texas Press.

Violence Reduction Unit. 2011. The Violence Must Stop: Glasgow's Community Initiative to Reduce Violence. Second year report. Glasgow: VRU.

\section{Appendix}

\section{Figure 1;}
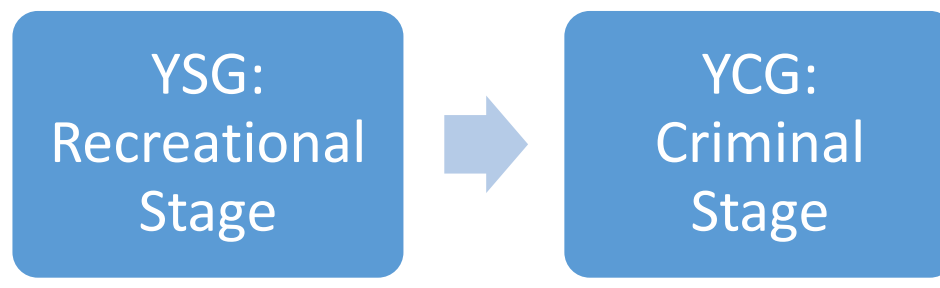

\section{SOCG: Syndicate Stage}

